\title{
REFLECTION
}

\section{Re-energizing VHS Collections, Expanding Knowledge: A Conversation about VHS Archives}

\author{
Alexandra Juhasz ${ }^{1}$ and Jennifer McCoy ${ }^{2}$ \\ 1 Film Department, Brooklyn College, US \\ 2 Art Department, Brooklyn College, US \\ Corresponding author: Alexandra Juhasz (Alexandra.Juhasz@brooklyn.cuny.edu)
}

Scholars, activists, researchers, and artists of a certain age and inclination are burdened with a soon-to-be-obsolete but always-beloved, carefully tended but perhaps recently quieted collection that most likely sits on an office shelf gaining dust: their VHS Archive. Not a personal collection, but a professional one of continuing or even growing value if not usability, this archive has been lovingly built and used, probably over decades, for teaching and research and in support of the movements and issues that have mattered most to the collector. With the help of an Open Education Resources grant from CUNY we built an online teaching resource for a graduate course that would focus on just twelve of these tapes. We hope that the course and its lasting website asks, and will offer some answers about, best practices for reactivating knowledge that might be endangered due to medium obsolescence, and other broader cultural factors of forgetting.

Keywords: VHS; Archives; AIDS; Activism; Art; Women; Sexuality; Videotape

\section{Introduction: VHS Archives}

In the spring of 2018, Brooklyn College Professors Alexandra Juhasz (Film) and Jenn McCoy (Art) co-taught an innovative course, VHS Archives, to twelve students from several graduate programs at CUNY (Performance and Interactive Media Arts, Screen Studies, Art History). Our aims went beyond the salvage and sharing of knowledge endangered through media obsolescence. Rather, we aimed for at-risk information to be reactivated by pedagogy and technology while aligning our students' original research, art, communitybuilding, and activism with the contemporary AIDS crisis. Our contribution to this special issue serves as a brief introduction to the syllabus and website for VHS Archives. Our personal reflections, written as teacher/artist/activists, look back on our goals, processes, and outcomes after having recently completed the course.

We hope this brief introduction also serves as a useful tool for engaging with the many course materials and exciting student contributions that were made during the course of the term. These projects were created in conversation with the digitized tapes but were connected to contemporary communities. By design, the course sought to engender the interpenetration of scholarly, artistic, and technological research practices and formats to expand knowledge, communication, power, and history about AIDS. This fertile admixture of art, activism, and analysis had also inspired the materials under close pedagogic consideration for the semester: twelve AIDS activist videotapes from the 1980s made by artists, activists, intellectuals, and educators. ${ }^{1}$ The tapes were made and then collected in the 1980s and early 1990 s as part of a larger collection, the media research materials for Juhasz's doctoral project on AIDS activist video. ${ }^{2}$ The course's website began with, and then was built from, a small subset of her imperiled AIDS media collection, which focuses on women, sex, and local vulnerable communities.

\footnotetext{
1 See Douglas Crimp, ed., AIDS: Cultural Analysis, Cultural Activism (Cambridge, MA: MIT Press, 1988).

2 See Alexandra Juhasz, AIDS TV: Identity, Community and Alternative Video (Durham, NC: Duke University Press, 1995).
} 
As is true for anything held on VHS tape, the window for salvaging particular knowledge held therein-in this case by and for queer, of color, feminist, AIDS media activists and their local communities-was quickly closing. In the meantime, the AIDS crisis continued, affecting women, people of color, poor people, children, prostitutes, people of the global south, and other vulnerable communities much as it had in the 1980s. It was our belief that these tapes might hold precarious know-how relevant not only to the history of queer, anti-racist, pro-sex, feminist, community-based organizing and art-making, but also strategies, legacies, and wisdom that could connect to and be useful for today's struggles and communities. Thus, the course was not merely meant to save and learn from these at-risk-of-certain-loss materials; it was organized to use those materials for analysis and to make new art, in close conversation with contemporary academia, art, community, and activism.

While pharmaceutical remedies have allowed HIV/AIDS to become a livable if serious medical condition for most people with access to quality health care and with a relatively stable life, significant numbers of humans do not and have never experienced HIV/AIDS in this way. Therefore, the twelve tapes for the course were selected to exemplify the significant variety of subcultures, activist concerns, and associated media approaches that had been critical during the first catastrophic decade of the AIDS crisis and that might still be relevant for today's most impacted communities. Tapes ranged in style from traditional documentaries to esoteric art videos, lesbian-feminist pornography and community-based educational projects. Communities addressed and represented ranged from Latina/os and African American women in Philadelphia to prostitutes' rights activists in California and children of color in New York City. We hoped that even for those students who entered the course with no or little initial commitment or connection to HIV/AIDS activism or studies, the set of materials would be small enough to first foster a shared knowledge of the collection and then to inspire an intimacy with its material that would move our students to connection and action. It is our sense that this aspect of the course was a success.

We also believed that digital technology was a necessary engine for such salvage, sharing, connection and (re)activation. Working with the Brooklyn College Library and a dedicated educational technologist, Emily Fairey, we digitized the tapes and then shared them with the students on a specially developed course website built using the Omeka platform (activismvhs.omeka.net). The purpose of the site was to link technology and pedagogy to facilitate the students' interaction with a small set of documents and to enable original research, group work, and discovery and sharing of associated resources, as well as to foster communitybased connections and make it possible for the project to continue to grow over cycles of use. Yes, the course website is an open educational repository for digitized tapes and associated course readings about AIDS cultural history, artistic uses and theories of archives, and best practices for the saving, annotating, and indexing of VHS tapes. But just as critically, it provides or links to tools and platforms that allow students to engage closely with each other and an interested public, not only with these course materials. We made connections to other scholarly media research platforms and collections and used the online learning space to allow our students to work closely with our tapes as well as tapes housed at other institutions (through the annotation tool available on Dartmouth's Media Ecology Project, for instance). Students could also upload new video material, adding to the body of media available for future study.

We intend for this brief reflection to serve as a useful précis to our syllabus, the students' completed assignments, and the course website and goals. Here you will find links to sources for best practices that we shared with our students and directions for the class projects (activismvhs.omeka.net/readings and activismvhs.omeka.net/projects). You can also look at the students' exercises (activismvhs.omeka.net/studentpage), the materials they found and shared with each other (both those made by others and those they made themselves for the course), and their final group projects, all inspired by (and referring to) one tape from the collection (activismvhs.omeka.net/exhibits). In the course, we spent a good deal of energy differentiating between, debating and specifying various types and uses of sets of research materials, particularly for artists and activists. You can see the students' various projects about and involved with archives as well.

We plan to teach the course again in the fall of 2020. As is true for any new course-but particularly one as eclectic, multifaceted, and ambitious as this one-there is much we can and will change, a great deal of which is technology- and/or community-dependent. In our conclusion, we will offer a few thoughts on ways we hope to improve the course, and also on how, as is so often the case, our initial ambitions outflanked our capacities. In some ways, the course took on too much in trying to strike a balance between archival research and artistic production, particularly with the mandate of using a technological interface for both. However, as educators interested in motivating our graduate students-as artists and intellectuals-to learn from, connect to, and try to change their world, especially during these most crushing of times, we believe that saving and using these nearly lost tapes inspired new work, community relationships, art, and connections, both personal and professional, that moved us and local communities to whom we connected, and will perhaps move you as well. 


\section{VHS Archives: Background and Goals (from Alexandra Juhasz)}

In my recent book, AIDS Crisis Revisitation and Conversational Stewardship, co-written with AIDS activist Theodore Kerr, we contemplate the liabilities of the up-to-now largely patrimonial stewardship of the AIDS media archive. ${ }^{3}$ It is our contention that records from the history of AIDS activism have largely been saved and cared for by institutions that strive to secure scholarship about and preservation of the history of gay white men. While the impact of AIDS on this community is indisputable and their initial projects of stewardship were invaluable, it is also certain that AIDS has played an equal role in both the devastation and related movements of other groups. What would it look like to start AIDS archival projects from the vantage of women's history, lesbian feminism, or black pride?

The framework of the class was built with an orientation to some of these other activist, intellectual, and community responses to AIDS. By including the tapes, the course resources, and the students' assignments and projects on an Omeka site, we made the course itself into a working, interactive, generative collection of materials focused on women and AIDS-a generative, flexible, open archive available to others who might need it. This grew from a larger salvage project inspired by the impending loss of my larger video collection. I learned that my VHS 'archive' was 300 tapes strong when I boxed, itemized, and moved it to New York in 2016. Seeing it anew, well aware of both its imminent demise and ongoing relevance, I decided to work with qualified colleagues to save and use it as one test case from which to learn and share some best practices for preserving, teaching with, and activating obsolete media.

The small scale of my collection also seemed important to me, as did its domain as a collection both personal and professional. I knew this pile of tapes, neither official archive nor hobby, looked much like those on many professors' office shelves (whatever the particular subject under study). That is to say, this collection had valuable knowledge for our teaching and research, collected and used over many years. In particular, I wanted to focus on the potential of slight but deep and complex media collections as possible counter-technologies. Given the problematic ethical, research, and social troubles of the gargantuan media holdings of today's corporate-owned social networks-cum-archives-com-shopping-malls that define much of our daily life, human interactions, and educational encounters, I was keen to work with small digital holdings of meaningful materials. ${ }^{4}$

In the spring of 2017, I began an informal working group to think about these questions, and with their support I decided to donate my 300 VHS tapes to the Brooklyn College Library. They are still being digitized and entered into the Library's holdings and offerings. With the help of an Open Education Resources grant from CUNY, overseen by Brooklyn College librarian Miriam Deutch, we began to activate some of the tapes for teaching, research, and community building. The course, its website, and our reflections-which follow below-ask, and offer some answers about, methods for locating, reactivating, building and connecting knowledge that is endangered due to medium obsolescence, including how to:

- Create, house, and organize a small digital collection built from a larger professional video collection about to be format-obsolete.

- Produce small VHS-to-digital archives as sharable, teachable resources, organized by and held in libraries (i.e., for this collection, at Brooklyn College, CUNY).

- Use one small, media-rich, content-heavy archive of VHS tapes of feminist, AIDS, experimental, anti-racist, avant-garde video from the 1980s-1990s as a test case for any such 'private' collection of media held originally in analogue formats.

- Teach from it.

- Share it with relevant groups within and outside of academia.

\section{Reflections on VHS Archives: Assignments, Collaboration and Community (from Jennifer McCoy)}

As an artist and educator, I consider the stewardship of avant-garde video of great importance. When I teach video art, the activity of screening, contextualizing, and extending the ideas found in video from 1965-present is a primary activity. Videos from this period are often housed only in the collections of the people who made them, or archived in institutional collections that have not had the time or resources to

\footnotetext{
${ }^{3}$ See 'Stacked on Her Office Shelves,' Alexandra Juhasz and Theodore Kerr, January 13, 2017, The CUNY Graduate Center, Center for Humanities Blog: https://www.centerforthehumanities.org/blog/stacked-on-her-office-shelf-stewardship-and-aids-archives.

4 This is also a major theme of my 2009-12 class and 'video-book,' Learning from YouTube (MIT Press, 2011), http://vectors.usc.edu/ projects/learningfromyoutube/.
} 
make them available for scholarly use. When Alex showed me a picture of her VHS archive, the handwritten labels and dusty dust jackets immediately reminded me of the urgency I had felt as I spent hours during my graduate school years dubbing material from the (possibly illicit collections of) screening copies of art videos belonging to every professor I had in graduate school. After my own graduate education ended, my collection of tapes continued to grow by mail as artists I knew sent me copies of works and works in progress. It was clear to me then, as it is now, that these titles are often difficult to find. Either because of the artificial scarcity demanded by the gallery system or because the artists' and makers' practices were too marginal to be preserved by an institution at all, many artists I love and admire would remain unknown to my students but for my precious dubs. I was also struck by many names I recognized and realized that one person's localized sphere of activism is another person's canonical reference. Part of my interest in teaching the class was to see how the artists' names I was familiar with through an art context had engaged with a wider emergent community of activism.

In my own practice, making work in collaboration with my longtime partner Kevin McCoy, I have made work that critiques and expands the idea of the archive. In works like Every Shot Every Episode (2001), we created a sculpture that contains discs of video appropriated from the television show Starsky and Hutch. We compiled individual shots into categories of moving images (like 'Every Pan Left' and 'Every Close Up') in an attempt to conflate the idea of narrative logic with the then-new idea of database logic. This and the cycle of similar projects that followed were my entry point to ideas about how artists both use existing archives and create new archives as mirrors of totalizing authoritarian modes of knowledge.

As a faculty member of both the Art Department and PIMA (Performance and Interactive Media) at Brooklyn College, I was excited to hear that Alexandra Juhasz was joining the Film Department. PIMA courses are primarily taught collaboratively and across disciplines, so an immediate point of interaction between us was her suggestion of a course for a Community Arts class that required interaction with community partners. The usual plan of action for this course is for students to work in groups to create works of art, often performance, with and about communities of people that they identify in the New York City metropolitan area. Examples of this include a group of dancers who worked with Brooklyn sanitation workers to choreograph and perform in their rotunda space à la Mierle Laderman Ukeles. In another class project, MFA students worked with a Brooklyn homeless population in a Polish neighborhood to stage tableaux vivants of famous religious Renaissance paintings. This event was followed by a community dinner.

For the VHS Archives class, then, co-taught as part of the PIMA program, our hope was not only to examine the archive Alex brought to the table, but also to challenge students to find ways that the ideas and/or strategies inherent in these tapes can be used to inspire art and activism today. Our goal was to model how community-based media archives sustain and define communities while also working to protect their political and aesthetic legacies. As the class progressed, it was clear that students were not only unfamiliar with some of the work we screened, but were also unaware of the circles of artistic and activist communities that formed the context for this work. By screening the videos and asking students to react artistically to this work in a contemporary community context, we felt the original intentions of the work were not only protected but extended.

To this end, the syllabus for the flow of the class contained multiple strategies. It began by asking students to present an archive with which they already felt connected. The students each created a presentation about materials ranging from the Dada archive housed at the University of Iowa to an interview with a man who has a comprehensive photo archive of American strip clubs. Using their own archival interests and commitments as a starting point, the class was able to discuss the difference between an archive, a collection, and a curation. Next, we asked the students to dig into Alex's collection of tapes online, and, using Mediathread (a platform developed by the Media Ecology Project at Dartmouth, which provides webbased tools for class-based annotation), the students enriched the archive for class use, and for the use of people outside the class, by annotations and tagging. During this period of annotation, the students were able not only to connect with tapes that spoke to them, but also to find others in the class group who were interested in the same material.

We are interested in making archives of old things usable for contemporary communities. The next step was to connect class groups with community partners by using their connections to each other vis-à-vis the video material. To jump-start this process, we invited representatives from two activist organizations, VOCAL-NY and Visual AIDS, to speak to the class. These presentations not only offered the possibility for students to extend the activist practices modeled in the content of the VHS archive into the present, but also grounded the class work, reminding us of why these practices are crucially relevant today and how they were always situated within communities who both made and needed them. Our students' first real creative efforts were 
to remix clips from the original archive, drawing out themes that interested them and developing a facility with found footage, montage, and recombinant media. At the same time, the images become theirs as well. Many of the performance students created live performances, combining on-stage action with projection and sound taken from the original VHS collection. Photos and video of the remix projects can be found in the Student Documents section of our website (activismvhs.omeka.net/collections/show/10).

Finally, the students connected with communities of their choice to devise group research projects that used archives and archiving to connect people around shared information, reveal hidden histories, or mobilize support. One group (Hot to Trot) linked existing contacts with the burlesque community to a history of activist sex worker performance art as embodied by Carol Leigh. The group not only referenced her early work in the Juhasz collection but also interviewed her in the present day and designed a suite of activist performances around her ideas. Another group worked with VOCAL - NY to create media in support of legislation for safe consumption sites. The group made video for VOCAL, attended protests, and invited the class to a protest that succeeded in changing Mayor Bill de Blasio's attention to pending legislation. A third group worked directly with a woman who was featured as a child in one of the twelve videos in our core collection. Their often unfruitful attempts to reach and engage this woman provided a useful case study in how difficult it can be for artists to work directly with people not involved in the arts, who struggle with everyday (or severe) problems of poverty, illness, and precarity. The students worked through the problem by instead using elements of the original video (by way of QR code) to connect with New York City youth in a park in Union Square. Links to final project descriptions and documentation can be found on the Omeka site.

Final Group Projects:

- 'Hot to Trot': activismvhs.omeka.net/exhibits/show/hot-to-trot-sex--activism--pe

- 'Release the Report': http://activismvhs.omeka.net/exhibits/show/release-the-report-a-collabor

- 'Dear J': http://activismvhs.omeka.net/exhibits/show/dear-j-

\section{VHS Archives: Conclusions}

Our course, VHS Archives, used a few of Alex Juhasz's tapes, as well as both of our larger commitments, connections, and histories, as one template for research and education about knowledge that is endangered by the losses of history and format. We asked our students to find, make, and share resources that might amplify the small personal holdings that initiated the effort. By housing the tapes and the students' work online, we changed one inaccessible collection into a vibrant flexible archive that we purposefully built together over a semester and then shared with interested outsiders.

While Omeka proved difficult to use, it did serve the function of warehousing and presenting items from our growing collection. Some of the student/artists found the Omeka structure and interface limiting. In many ways, we were trying to use a tool of library science to undergird an artistic experiment. As is usual, artists find ways to immediately break (or at least push the boundaries of existing technology. We imagine a future class that will begin with this new collection, one much larger than its founding 12 tapes and a semester's worth of related readings. We would like to streamline the format for accessing the documentation for the class and linking directly to the media that inspired it. We also would like to find ways to publicize and connect the site to make it useful to students, community activists, scholars and artists. Nonetheless, in its current form, we already find rich resources that include videos of performances, photos of activist demonstrations in which the class participated, and videos made for non-profit efforts toward drug policy change. This small archive has grown, and it is no longer a dusty holding of curious things from and of the past. Rather, through attention and activation, these endangered objects link to concerns, communities, and artistic practices of today.

\section{Competing Interests}

The authors have no competing interests to declare. 
How to cite this article: Juhasz, Alexandra and Jennifer McCoy. 2018. Re-energizing VHS Collections, Expanding Knowledge: A Conversation about VHS Archives. KULA: knowledge creation, dissemination, and preservation studies 2(1): 21. DOI: https://doi.org/10.5334/kula.24

\section{Submitted: 20 February $2018 \quad$ Accepted: 01 August $2018 \quad$ Published: 29 November 2018}

Copyright: (c) 2018 The Author(s). This is an open-access article distributed under the terms of the Creative Commons Attribution 4.0 International License (CC-BY 4.0), which permits unrestricted use, distribution, and reproduction in any medium, provided the original author and source are credited. See http://creativecommons.org/ licenses/by/4.0/

luI KULA: Knowledge creation, dissemination, and preservation studies is a peer-reviewed open access journal published by Ubiquity Press. 